ORNL/TM-2009/251

\title{
Safety Assessment of PowerBeam Flywheel Technology
}

\section{October 2009}




\section{DOCUMENT AVAILABILITY}

Reports produced after January 1, 1996, are generally available free via the U.S. Department of Energy (DOE) Information Bridge.

Web site http://www.osti.gov/bridge

Reports produced before January 1, 1996, may be purchased by members of the public from the following source.

National Technical Information Service

5285 Port Royal Road

Springfield, VA 22161

Telephone 703-605-6000 (1-800-553-6847)

TDD 703-487-4639

Fax 703-605-6900

E-mail info@ntis.fedworld.gov

Web site http://www.ntis.gov/support/ordernowabout.htm

Reports are available to DOE employees, DOE contractors, Energy Technology Data Exchange (ETDE) representatives, and International Nuclear Information System (INIS) representatives from the following source.

Office of Scientific and Technical Information

P.O. Box 62

Oak Ridge, TN 37831

Telephone 865-576-8401

Fax 865-576-5728

E-mail reports@adonis.osti.gov

Web site http://www.osti.gov/contact.html

This report was prepared as an account of work sponsored by an agency of the United States Government. Neither the United States Government nor any agency thereof, nor any of their employees, makes any warranty, express or implied, or assumes any legal liability or responsibility for the accuracy, completeness, or usefulness of any information, apparatus, product, or process disclosed, or represents that its use would not infringe privately owned rights. Reference herein to any specific commercial product, process, or service by trade name, trademark, manufacturer, or otherwise, does not necessarily constitute or imply its endorsement, recommendation, or favoring by the United States Government or any agency thereof. The views and opinions of authors expressed herein do not necessarily state or reflect those of the United States Government or any agency thereof. 
Materials Science and Technology Division

\title{
Safety Assessment of PowerBeam Flywheel Technology
}

\author{
J. M. Starbuck \\ J. G. R. Hansen
}

October 2009

\author{
Prepared for \\ Hybrid Electric Systems, Vehicle Technologies Program, \\ Office of Energy Efficiency and Renewable Energy, \\ Department of Energy \\ Prepared by \\ OAK RIDGE NATIONAL LABORATORY \\ Oak Ridge, Tennessee 37831-6285 \\ managed by \\ UT-BATTELLE, LLC \\ for the \\ U.S. DEPARTMENT OF ENERGY \\ under contract DE-AC05-00OR22725
}


This page left blank intentionally. 


\section{TABLE OF CONTENTS}

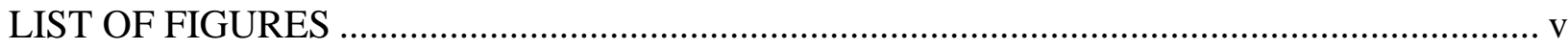

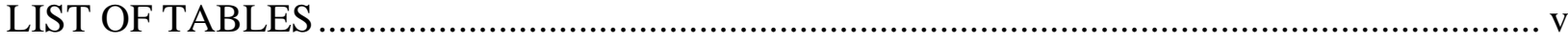

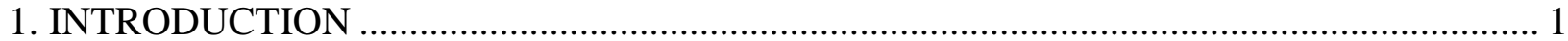

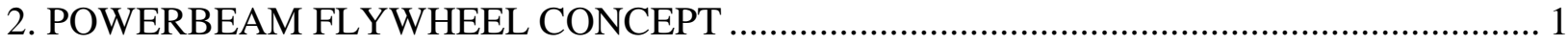

3. POWERBEAM FLYWHEEL POINT DESIGN FOR EVALUATION ................................. 2

4. ORNL DESIGN ANALYSIS AND SAFETY EVALUATION …...................................... 3

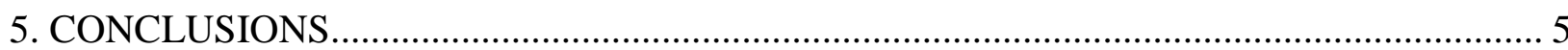

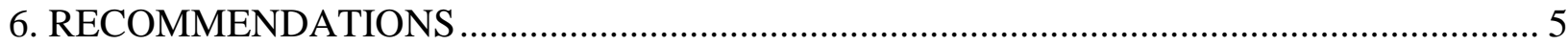

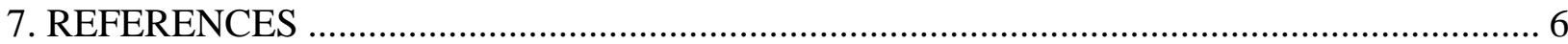

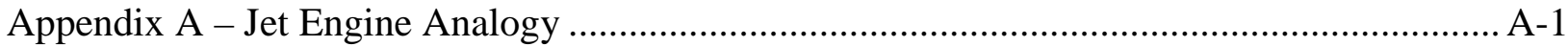

Appendix B - Nested Ring Analysis of PowerBeam Rim ................................................ B-1

Appendix C - Finite Element Analysis of PowerBeam Rotor ............................................. C-1 
This page left blank intentionally. 


\section{LIST OF FIGURES}

Figure 1. Main HyKinesys PowerBeam Components ......................................................... 2

Figure B-1. Hoop stress and weight versus tip speed ...................................................... B-2

Figure C-1. Sketch of energy storage design concept........................................................ C-2

Figure C-2. Axi-symmetric finite element mesh ............................................................... C-3

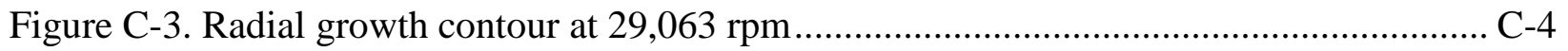

Figure C-4. Hoop stress contour at 29,063 rpm............................................................... C-5

Figure C-5. Von Mises stress contour at 29,063 rpm .......................................................... C-6

\section{LIST OF TABLES}

Table 1. Comparison between closed-form and finite element results .................................... 4

Table B-1. Tabulated data plotted in Figure B-1 .............................................................. B-2 
This page left blank intentionally. 


\section{INTRODUCTION}

By far the greatest technical challenge facing the developer of mobile flywheel systems for transportation is the issue of safety. A Partnership for a New Generation of Vehicles (PNGV) hearing report ${ }^{1}$ contains the following entries concerning flywheel safety:

- "With respect to safety, it is not clear that a satisfactory solution has been found to the problem of burst containment. It may be that avoidance of catastrophic burst - rather than burst containment - is necessary for industry and public acceptance.” (p. 235)

- "From both a customer acceptance and a product liability standpoint, it may be necessary for vehicle manufacturers to make flywheels "fracture proof," that is, to eliminate the possibility they could come apart in a catastrophic fashion.” (p. 273)

For vehicular applications, it is extremely difficult to design a lightweight, low cost containment system which can contain a full, high speed composite rotor burst failure. Therefore an approach consistent with the previously quoted comments from the PNGV Program is to establish designs and operating procedures such that full rotor burst failure modes are avoided. This is analogous to a gas turbine jet engine design in which a catastrophic compressor disk failure is avoided by conservative design of the rotor (Appendix A).

\section{POWERBEAM FLYWHEEL CONCEPT}

Flywheel technology has traditionally been applied to vehicular transportation in the form of a single disk type flywheel in which the flywheel rim diameter is greater than its length. If a flywheel's aspect ratio is defined as:

Aspect Ratio $=\mathrm{L} / \mathrm{D}$

where: $\mathrm{L}=$ rotor length and $\mathrm{D}=$ rotor outer diameter

then traditional flywheels are said to have a low aspect ratio $(<1)$. The PowerBeam flywheel system concept, developed by HyKinesys Inc., employs flywheels with a high aspect ratio $(>1)$ for which the rotor length is greater than the diameter. Rotor stability issues preclude a flywheel from having close to an equal diameter and length (aspect ratio $=1$ ). It has been theorized that the high aspect ratio of the PowerBeam flywheel leads to a safer flywheel system.

The PowerBeam flywheel system concept employs a pair of counter-rotating, high aspect ratio flywheels. The concept is demonstrated in Figure 1. The two PowerBeam flywheels are shown in the figure mated to an all-mechanical infinitely variable transmission (IVT), but alternatively the flywheels could also have been coupled to the electro-mechanical IVT shown separately.

The PowerBeam approach to safety is to design conservative flywheels so as to avoid full rotor burst failure modes. The high aspect ratio rotors are deliberately over-engineered and only lightly stressed in use. This approach involves designing with a significant stress margin between operating stress and ultimate stress. The designer must, of course, consider radial and axial stresses in addition to the large hoop stresses. Using a rotor design with a large stress 
margin can result in long rotor life. The designer must include consideration of stress life and cyclic fatigue failure modes during detailed design.

\section{Main HyKinesys PowerBeam Components}

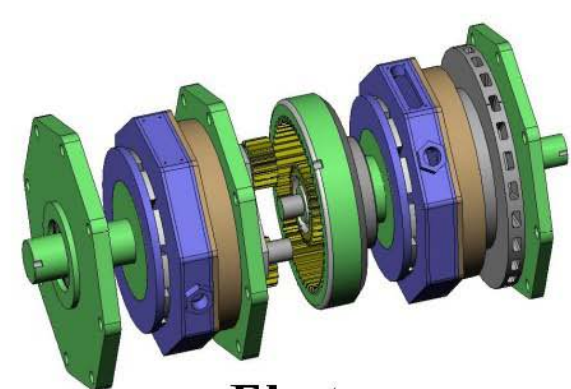

Electro-

Allmechanical mechanical IVT

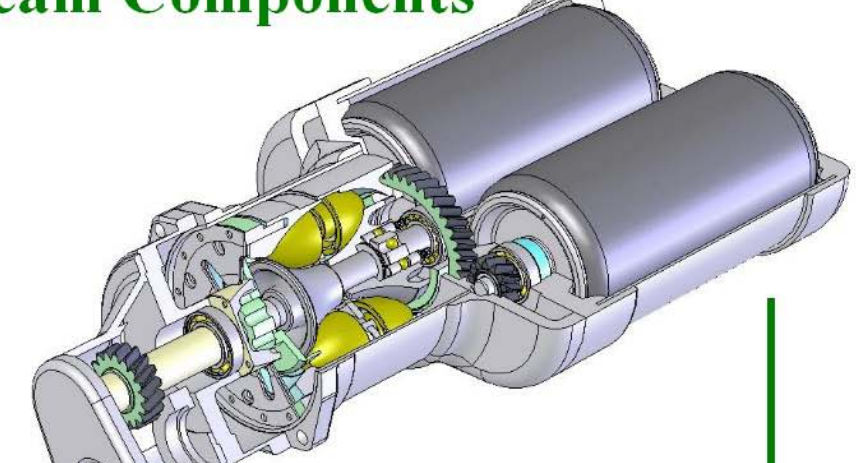

Fits in spare wheel well, under the trunk; connects to the final drive

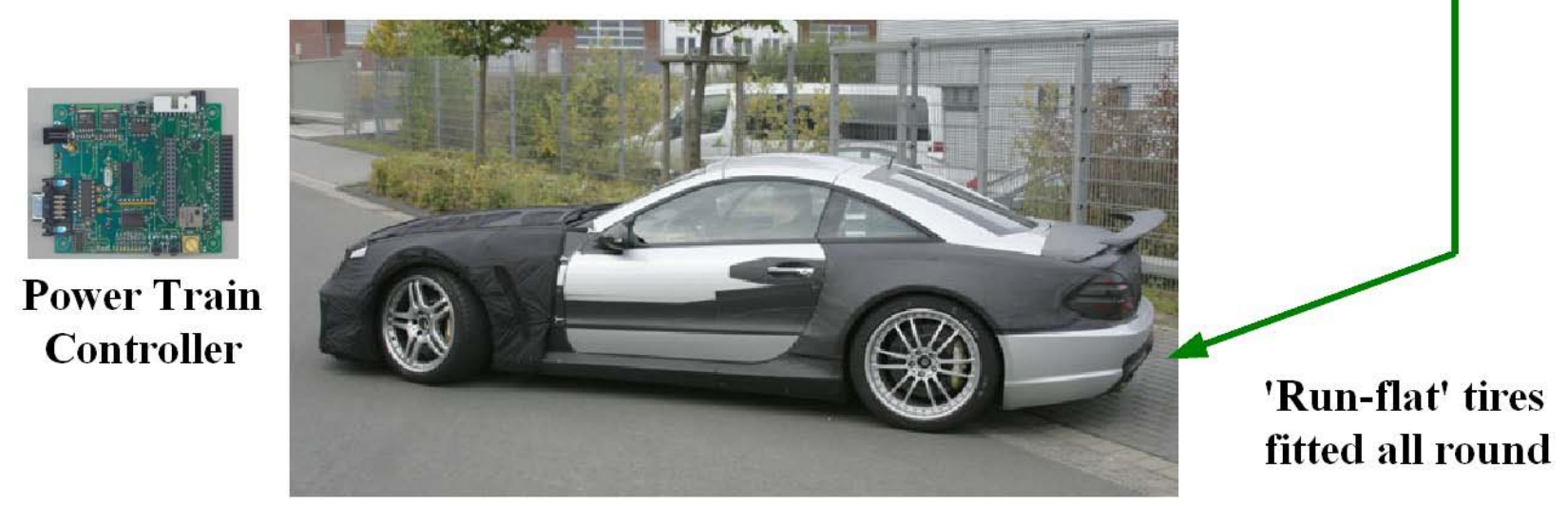

Figure 1. Main HyKinesys PowerBeam Components.

Using either of the transmissions shown in Figure 1, the PowerBeam concept developer, Chris Ellis, predicts that in an initial PowerBeam application at least $60 \%$ of the energy from regenerative braking at urban speeds can be recovered, with an eventual realistic target of $80 \%$. This compares well with the 35\% peak regenerative braking efficiency for today's hybrid vehicles. These predictions allow for the weight of the PowerBeam flywheel system in the vehicle, accommodating the weight of the conservative design analyzed below.

\section{POWERBEAM FLYWHEEL POINT DESIGN FOR EVALUATION}

A conservative PowerBeam point design was developed by HyKinesys for stress analysis by the Oak Ridge National Laboratory (ORNL). The point design was sized for use in a mid-size sedan such as a Chevrolet Malibu or larger. The PowerBeam rotor rims were constructed of a steel tube covered by a carbon fiber reinforced polymer matrix composite tube. Performance information for the PowerBeam flywheel system analyzed by ORNL follows: 
- Composite Fiber Strength

(Hexcel IM7 fiber in 6K filament tow)

- Composite Tensile Allowable

- Steel Yield Strength (4340 Steel)

- Mass of One Rim

- Maximum Rim Peripheral Speed

- Stored Energy of One Rim

- Stored Energy of Two Rims

- Delivered Energy of Two Rims
5310 MPa (770 ksi)

$3190 \mathrm{MPa}(462 \mathrm{ksi})$

$1500 \mathrm{MPa}(217 \mathrm{ksi})$

$18.0 \mathrm{~kg}(39.6 \mathrm{lb})$

$350 \mathrm{~m} / \mathrm{sec}(1150 \mathrm{ft} / \mathrm{s})$

$0.929 \mathrm{MJ}(258 \mathrm{Wh})$

$1.86 \mathrm{MJ}(516 \mathrm{Wh})$

$1.40 \mathrm{MJ}$ (387 Wh)

The above values assume that energy is delivered by slowing two full speed rims to half speed without losses , and as such the delivered energy is equivalent to $3 / 4$ of the stored energy.

Composite material allowables above have not been degraded by elevated temperature, since the PowerBeam uses the concept of 'cold' rotors. The only source of heat within the vacuum chamber surrounding each rotor is windage from the rotation of the rotor. Because rotor speeds are relatively low, vacuum seals can be used which allow the bearings to be outside the vacuum and oil cooled and lubricated, which also helps ensure long bearing life. A level of vacuum will be used which will keep windage losses to a minimum and consequently minimize heat build up. The relatively large surface area of the metal casing will provide an effective route for the low rate of heat output resulting from windage. An abnormal heat level will be an early indicator of some form of failure, and sensors will be fitted to allow this to be picked up and initiate an orderly shutdown. The temperature at which shutdown will commence will be well below the level at which the properties of the composite materials significantly degrade. Because two identical rotors are used, any significant deviation between the readings from the two sensors will help guard against the potentially serious consequences of sensor failure.

\section{ORNL DESIGN ANALYSIS AND SAFETY EVALUATION}

ORNL has significant experience in design, fabrication and testing of composite rotors. Rotor design analyses usually begin with use of concentric cylinder (nested ring) design codes to provide an initial evaluation of a flywheel rotor and a preliminary estimate of its factor of safety. In this manner stresses in the flywheel material layers were estimated in a preliminary manner to establish the feasibility of the PowerBeam flywheel rotor to withstand centrifugal loading. Results of the analysis provided the dimensions of the various material layers in the flywheel rim. Results in Table 1 under the column labeled "Closed-Form" are the final results of an iterative series of runs of the nested ring code. Details of nested ring analysis results are included in Appendix B.

Following the preliminary analyses just described, a preliminary finite element analysis was completed to assess the design concept in more detail. An approximate geometry was assumed for the arbor connecting the rotor rim to a central shaft. The finite element model is depicted in figures in Appendix C. Symmetry was assumed about the mid-length of the rim and an axisymmetric finite element mesh was used for the analysis. This was a simplified initial look at the design so all of the mating surfaces were assumed to remain in contact at the spin speed. 
Therefore, the mating surfaces between the arbor and the inner metal ring and between the inner metal ring and the outer composite ring were modeled using coupled displacements.

Results were calculated for radial growth, hoop stress, and Von Mises stress contours. The far field rim results, i.e., away from the rotor ends, are in excellent agreement with the closed-form nested ring results (see "Finite Element” column in Table 1). The steel inner rim tube is comparatively more highly stressed than the composite outer tube. The safety factor of the composite material is 7 , while that of the steel is greater than 3 . It should be noted that the steel rim alone, without a composite overwrap, would not yield until a spin speed of $470 \mathrm{~m} / \mathrm{s}$ is reached, so it could function at the $350 \mathrm{~m} / \mathrm{s}$ operating speed without the composite overwrap and still have a safety factor of 1.85. The composite overwrap allows the steel rim to achieve a more conservative design with a high safety factor of 3. Details of finite element analysis results are included in Appendix C.

Table 1. Comparison between closed-form and finite element results

\begin{tabular}{|c|c|c|c|}
\hline Result & $\begin{array}{c}\text { Closed-Form } \\
\text { (Nested Ring) }\end{array}$ & $\begin{array}{c}\text { Finite Element } \\
\text { (Far Field) }\end{array}$ & Safety Factor \\
\hline Steel ring hoop stress (MPa) & 481 & 486 & 3.09 \\
\hline Composite ring hoop stress (MPa) & 457 & 454 & 7.02 \\
\hline Radial growth (mm) & 0.243 & 0.243 & \\
\hline
\end{tabular}

The safety factor of 7 for the composite material can be related to past PNGV developments reported in Reference 2 that called for a safety factor of about 4 . A passage from page 45 of Reference 2 is repeated below.

"A key development is the design of an adequate containment mechanism in the case of failure. The flywheel technical team has followed several strategies and has essentially overcome this significant barrier. Perhaps the most important advance is the growing evidence that flywheels (or portions thereof) that fail at low stress-to-strength ratios do not "burst" but remain intact. This knowledge dictates that the rotating parts have a high ultimate strength-to-maximum operating stress ratio (about 4:1).

Retaining "loose flywheels" is significantly easier than containing fragments because of the increased time for energy dissipation. The new design strategy for flywheel housings are designed to retain loose flywheels and contain fragments from partial flywheel failures instead of containing a complete burst and disintegration of a flywheel. This design strategy also attempts to manage energy as it dissipates. Limiting the use of flywheels to fast-response power plants reduces the energy storage requirements and permits the design to meet the safety goal for strength-to-stress ratio with a manageable increase in weight.”

The PowerBeam safety factor of 7 for composite material compares favorably with the safety factor of about 4 cited above in the PNGV flywheel development program. 
Finite element analysis in Appendix $\mathrm{C}$ was also used to evaluate the rotor arbor. A preliminary model shows that the arbor overly constrains the rim section of the rotor. A redesign of this interface will better match the growth characteristics of the two parts. The maximum hoop stress of $626 \mathrm{MPa}$ in the metal parts occurs in the arbor rather than the rim. The safety factor for the steel arbor is thus 2.40, but improved designs may be possible that reduce this stress level. It should be noted that HyKinesys supplied only an indicative arbor design, and that work continues to develop an arbor which delivers a higher safety factor. However, the key objective, a flywheel rim which will 'never' burst, has already been achieved analytically. To assure that the flywheel rim 'never' fails, a test program is necessary. However, since there already are large IC engine flywheels and very high speed turbocharger rotors that 'never' burst when operating in vehicles, we believe that the same level of safety that applies to these components can be established for the PowerBeam flywheel design documented in this report.

\section{CONCLUSIONS}

- The composite material in the PowerBeam flywheel has a safety factor of 7 that is significantly above the minimum of 4 suggested in the PNGV report ${ }^{2}$ to prevent burst and disintegration of the flywheel.

- A loose flywheel and fragments from a partial flywheel failure needs to be contained in the structure of an adequately designed vacuum housing, shown schematically in Figure 1. Containment of a loose flywheel or flywheel fragments is significantly easier than containing a burst flywheel.

\section{RECOMMENDATIONS}

- To prove whether or not a loose flywheel or fragments from a partial flywheel failure can be contained within the PowerBeam vacuum housing that envelope the counter-rotating flywheels, a test program is needed.

- A test program would ideally involve application of a severe impact load on an operating pair of counter-rotating flywheels. For instance, the German bus producer Magnet Motor, GmbH subjected their conservatively designed flywheel to a sudden side load of $15 \mathrm{~g}$ to simulate the loads of a vehicle collision, and their flywheel system survived the test.

- More analytical modeling effort in conjunction with testing can reduce the number of tests needed in order to make a test program manageable. 


\section{REFERENCES}

1. The Partnership for a New Generation of Vehicles (PNGV): Assessment of Program Goals, Activities and Priorities, Hearing Before the Subcommittee on Energy and Environment of the Committee on Science, U.S. House of Representatives, July 30, 1996 [No. 75].

2. Review of the Research Program of the Partnership for a New Generation of Vehicles: Fourth Report by Standing Committee to Review the Research Programs of the Partnership for a New Generation of Vehicles, National Research Council, National Academy Press, Washington D.C., 1998. 
This page left blank intentionally. 


\section{Appendix A - Jet Engine Analogy}

Gas turbine jet engines run at very high speeds and are designed to operate with low risk. The general public accepts the risk associated with jet engine failures. Risk in this case is maintained at a low level by a combination of conservative design, certification, manufacturing controls, inspections, operating procedures, and maintenance. With a gas turbine engine, a containment shroud is provided to contain broken blades, but the shroud is not designed to contain a rotor hub (disk) failure. Jet engine designers must make sure that hub failures never happen by building an adequate safety factor into the operating stress, resulting in a conservative, safe design. A hub failure in a jet engine is catastrophic to the aircraft and can be analogous to a rotor burst mode failure for a flywheel. A flywheel design conservative enough that the rotor cannot burst is analogous to the gas turbine engine design conservative enough that the rotor hub (disk) cannot fail. 
This page left blank intentionally. 


\section{Appendix B - Nested Ring Analysis of PowerBeam Rim}

Concentric cylinder (nested ring) design codes are used to provide an initial evaluation of a flywheel rotor and a preliminary estimate of its factor of safety. The code is based on closedform solutions of loaded concentric cylinders. For the PowerBeam rim analysis a composite cylinder was fit over a steel cylinder. In this manner stresses in the flywheel material layers were estimated in a preliminary manner to establish the feasibility of the PowerBeam flywheel rotor to withstand centrifugal loading. Results of the analysis provided the dimensions of the various material layers in the flywheel rim.

\section{Composite Ring Over Steel Ring:}

Mass of One $\operatorname{Rim}=39.6$ lbs. $=18.0 \mathrm{~kg}$

Stored Energy of One Rim= 0.929 MJ = 258 Wh

Accounts for kinetic energy stored in both composite and steel materials

Total Stored Energy of Two Rims $=258 \times 2=516 \mathrm{Wh}$

Estimated Total Stored Energy from Rotor Other Than Rim, = 5\% x 516 = 25.8 Wh

Estimated Total Delivered Energy $=3 / 4(516+25.8)=406 \mathrm{Wh}$

Energy delivered in slowing from full to $1 / 2$ speed equals $3 / 4$ of stored energy

Radial Growth at I.D. $=0.00956$ in. $=0.243 \mathrm{~mm}$

Composite Ring Maximum Hoop Stress $=66.0 \mathrm{ksi}=457 \mathrm{MPa}$

Steel Ring Maximum Hoop Stress = 69.7 ksi = 481 MPa

\section{Steel Ring Only:}

Mass of One Ring $=13.8 \mathrm{~kg}$

Stored Energy of One Ring = $192 \mathrm{Wh}$

Maximum Hoop Stress $=118 \mathrm{ksi}=812 \mathrm{MPa}$

Higher Peripheral Speed Design Points (Applies to Figure B-1 and Table B-1):

Fixed O.D. $=230 \mathrm{~mm}$

Fixed Composite Ring Thickness $=8 \mathrm{~mm}$

Fixed Stored Energy in One Rim = $258 \mathrm{Wh}$ 
Variables $=$ Steel Ring Thickness and Peripheral Speed

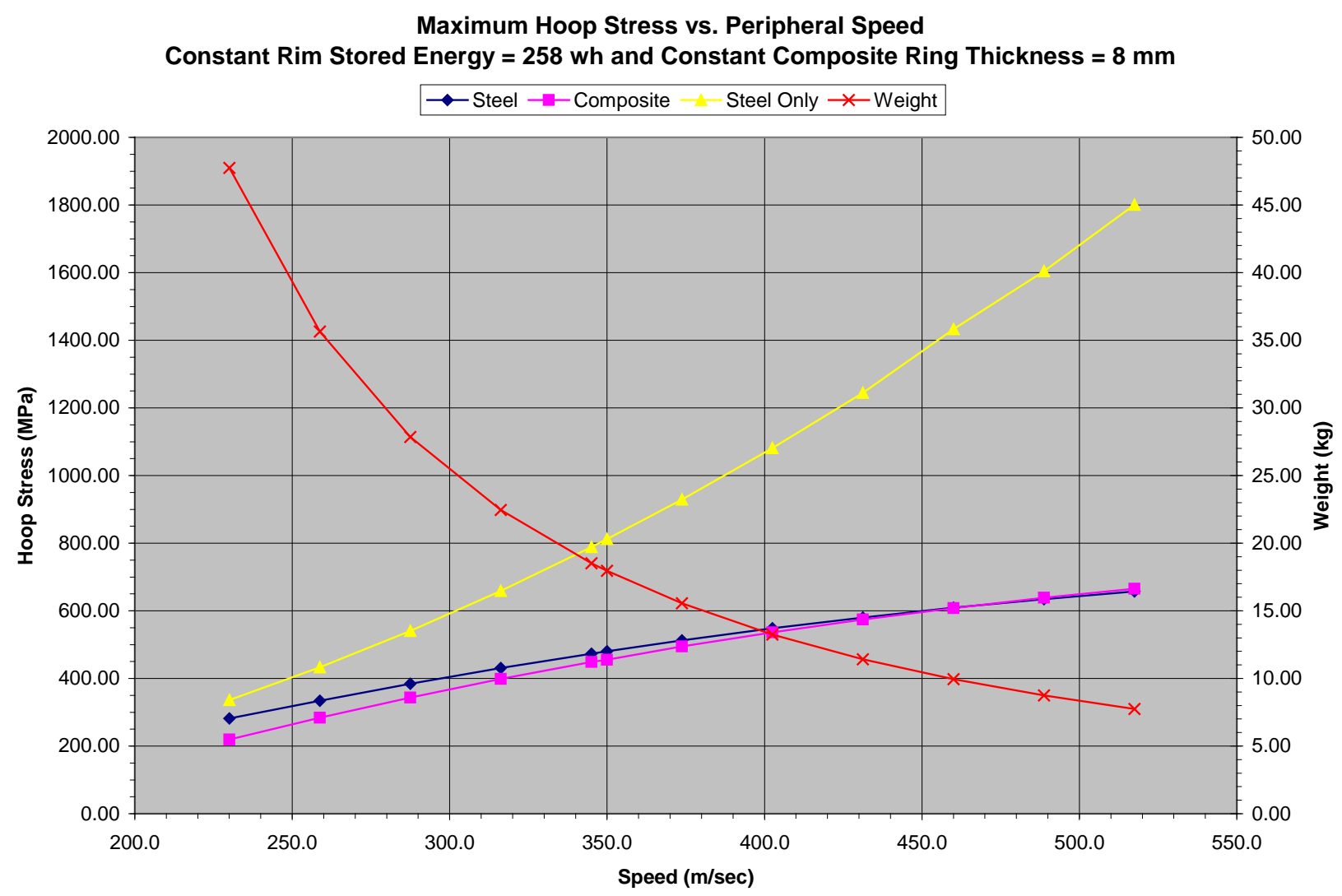

Figure B-1. Hoop stress and weight versus tip speed.

Table B-1. Tabulated data plotted in Figure B-1

\begin{tabular}{|c|c|c|c|c|c|c|}
\hline \multirow{3}{*}{$\begin{array}{l}\text { Angular } \\
\text { Speed }\end{array}$} & \multirow{3}{*}{$\begin{array}{c}\text { Tip } \\
\text { Speed }\end{array}$} & & \multirow{2}{*}{$\begin{array}{l}\text { Steel } \\
\text { Ring }\end{array}$} & \multicolumn{3}{|c|}{ Hoop Stresses } \\
\hline & & Rim & & & & Steel \\
\hline & & Mass & Thickness & Steel & Comp. & Only \\
\hline (RPM) & (m/sec) & $\begin{array}{c}\mathrm{m} \\
(\mathrm{kg})\end{array}$ & $\begin{array}{c}t_{\mathrm{s}} \\
(\mathrm{mm})\end{array}$ & $\begin{array}{c}\sigma_{\mathrm{h}} \\
(\mathrm{Mpa})\end{array}$ & $\begin{array}{c}\sigma_{\mathrm{h}} \\
(\mathrm{Mpa})\end{array}$ & $\begin{array}{c}\sigma_{\mathrm{h}} \\
(\mathrm{Mpa})\end{array}$ \\
\hline 19099 & 230.0 & 47.75 & 20.39 & 281.83 & 219.21 & 335.91 \\
\hline 21486 & 258.8 & 35.64 & 14.27 & 334.28 & 283.90 & 432.73 \\
\hline 23873 & 287.5 & 27.85 & 10.54 & 384.02 & 343.44 & 540.26 \\
\hline 26261 & 316.3 & 22.45 & 8.04 & 430.47 & 398.33 & 658.77 \\
\hline 28648 & 345.0 & 18.52 & 6.25 & 473.43 & 448.75 & 788.37 \\
\hline 29063 & 350.0 & 17.95 & 6.00 & 480.64 & 455.29 & 812.02 \\
\hline 31035 & 373.8 & 15.55 & 4.93 & 512.62 & 494.69 & 929.10 \\
\hline 33423 & 402.5 & 13.25 & 3.91 & 548.25 & 536.43 & 1081.07 \\
\hline 35810 & 431.3 & 11.42 & 3.11 & 580.24 & 574.04 & 1244.20 \\
\hline 38197 & 460.0 & 9.95 & 2.47 & 608.98 & 607.93 & 1432.71 \\
\hline 40585 & 488.8 & 8.74 & 1.95 & 634.71 & 638.41 & 1604.05 \\
\hline 42972 & 517.5 & 7.74 & 1.52 & 657.39 & 665.54 & 1800.84 \\
\hline
\end{tabular}




\section{Appendix C - Finite Element Analysis of PowerBeam Rotor}

A preliminary finite element analysis was completed to assess the design concept for mating the energy storing rim to the drive motor through a metal end plug. An approximate geometry was assumed for the plug, and an outline sketch of the design is shown in Figure C-1. Symmetry was assumed about the mid-length of the rim and the axi-symmetric finite element mesh that was used for the analysis is shown in Figure C-2. This was a simplified initial look at the design so all of the mating surfaces were assumed to remain in contact at the spin speed of 29,063 rpm. Therefore, the mating surfaces between the end plug and the inner metal ring and between the inner metal ring and the outer composite ring were modeled using coupled displacements.

Results are provided in Figures C-3 to C-5 for the radial growth, hoop stress, and Von Mises stress contours, respectively. The far field rim results, i.e., away from the end plug, are in excellent agreement with the closed-form nested ring results (see comparison in Table 1). At the plug end of the model, you can see from the shape of the deformed mesh and from the radial growth contour that coupling displacements results in a situation where matching the plug growth overly constrains the rim section. A redesign of this interface will be required to better match the growth characteristics of the two parts. Also, the maximum hoop stress of $626 \mathrm{MPa}$ occurs in the plug, not the rim. This is still within the assumed allowable (safety factor $=2.40$ ) but improved designs may be possible that reduce this stress level. 


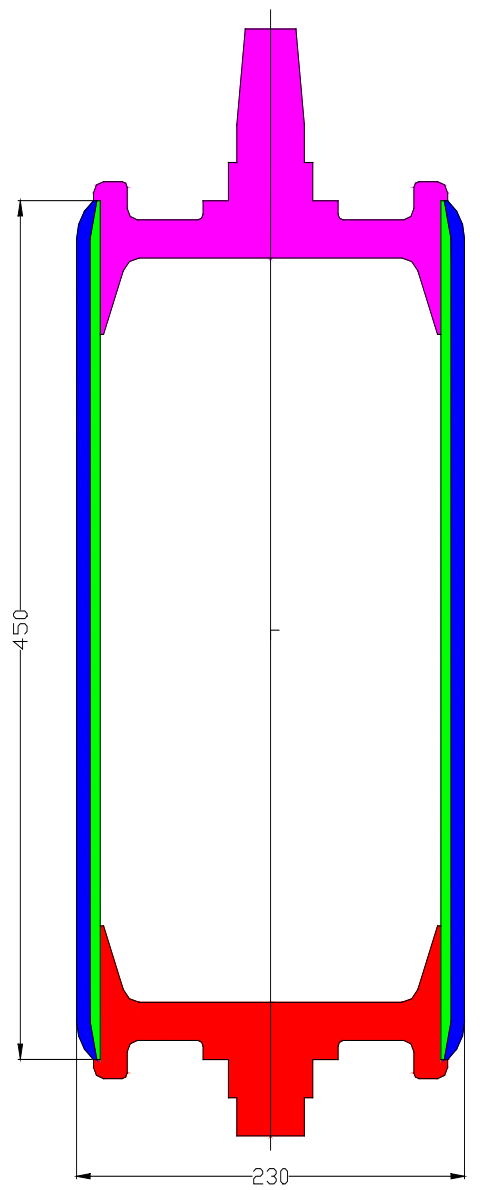

Figure C-1. Sketch of energy storage design concept. 


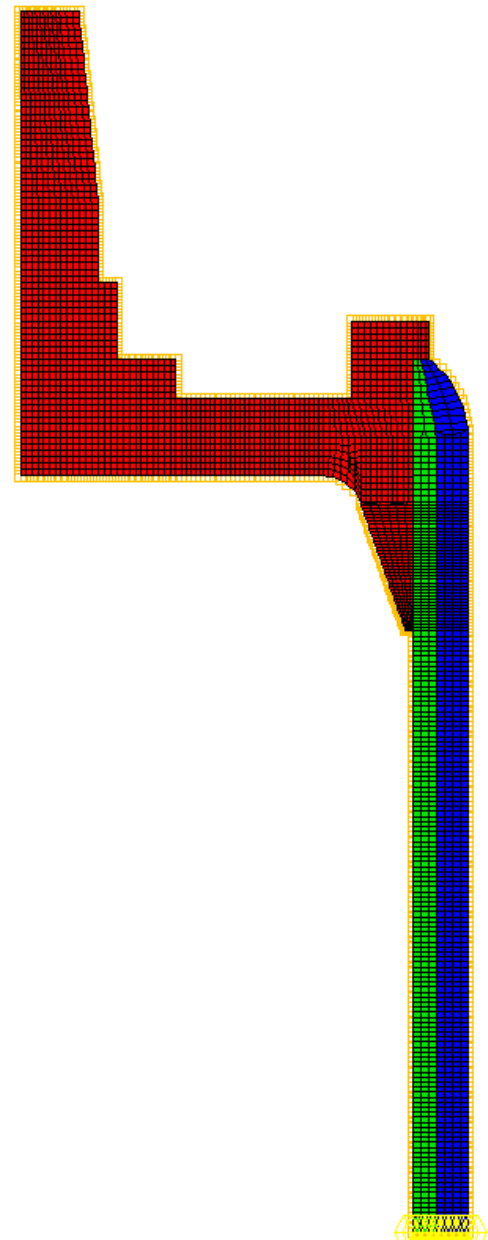

Figure C-2. Axi-symmetric finite element mesh. 
$X$ - DISPLACEMENT

VIEW : -.0004502 RANGE : 0.2495876
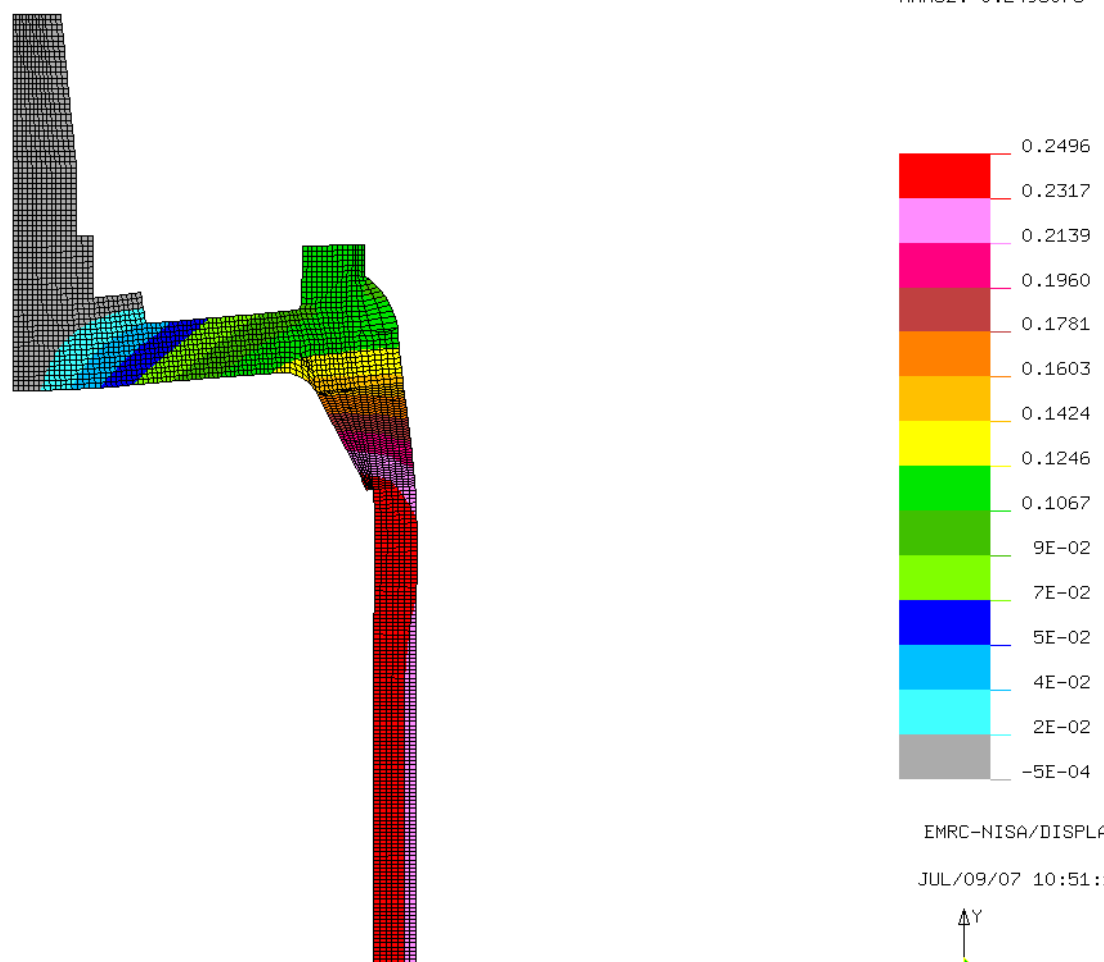

EMRC-NISA/DISPLAY JUL/09/07 10:51:11

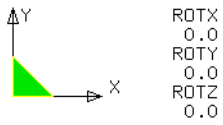

Figure C-3. Radial growth contour at 29,063 rpm. 

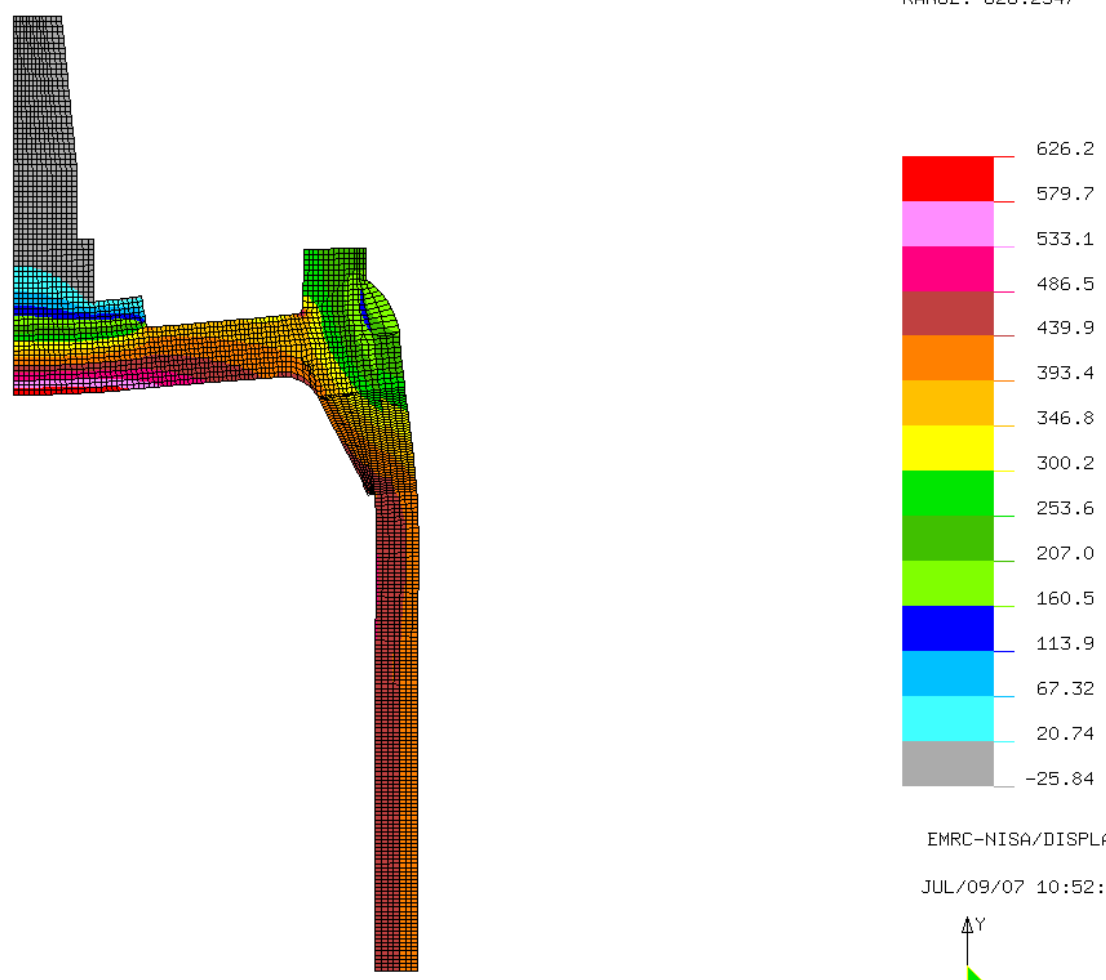

EMRC-NISA/DISPLAY JUL/09/07 10:52:04

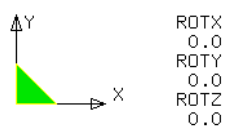

Figure C-4. Hoop stress contour at 29,063 rpm. 

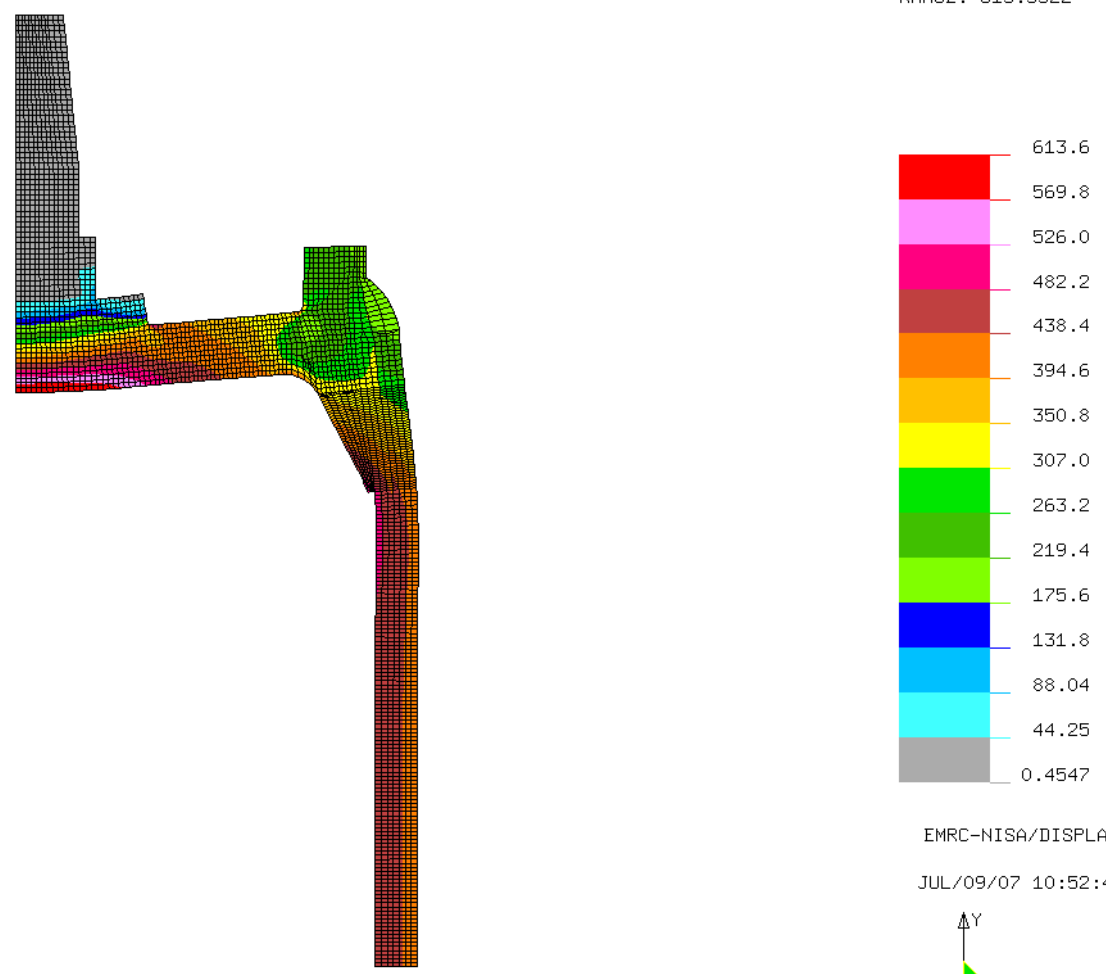

EMRC-NISA/DISPLAY JUL $/ 09 / 07 \quad 10: 52: 41$

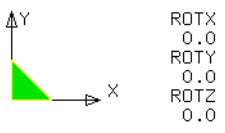

Figure C-5. Von Mises stress contour at 29,063 rpm. 


\section{INTERNAL DISTRIBUTION}

1. P. J. Blau

2. R. G. Boeman

3. C. C. Eberle

4. R. L. Graves

5. G. M. Ludtka

6. R. E. Norris, Jr.

7. M. Olszewski

8. F. L. Paulauskas

9. P. S. Sklad

10. D. E. Smith

11. J. M. Starbuck

12. C. D. Warren

13. K. D. Yarborough

14. S. J. Zinkle

\section{EXTERNAL DISTRIBUTION}

15. T. Q. Duong, U.S. Department of Energy, EE-2A/L'Enfant Plaza Building, 1000 Independence Ave., S.W., Washington, DC 20585-1615

16. Dave Howell, U.S. Department of Energy, EE-2G/Forrestal Building, 1000 Independence Ave., S.W., Washington, DC 20585

17. L. A. Slezak, U.S. Department of Energy, EE-2G/Forrestal Building, 1000 Independence Ave., S.W., Washington, DC 20585 